\title{
Cardiovascular Effects of Propranolol in Intact Puppies and Adult Dogs
}

\author{
Nestor J. Trugcone ${ }^{[34]}$ and O. Robert Levine \\ Department of Pediatrics, Columbia University College of Physicians and Surgeons, New York, New York, USA
}

\begin{abstract}
Extract
The cardiovascular effects of propranolol (Inderal) [24] were compared in 13 adult dogs and 14 puppies. Left ventricular $(\mathrm{LV})$ pressure was measured with a catheter tip manometer and myocardial contractility was assessed by LV measurements of peak rate of pressure development $(\mathrm{LV} \mathrm{dp} / \mathrm{dt}), \mathrm{LV} \mathrm{dp} / \mathrm{dt}$ at $40 \mathrm{~mm} \mathrm{Hg} \mathrm{LV}$ pressure $\left(\mathrm{P}_{40}\right.$ $\mathrm{dp} / \mathrm{dt}$ ), and peak LV (dp/dt)/P. Cardiac output was measured by indocyanine green dye dilution. Measurements were made before and $5 \mathrm{~min}$ after intravenous propranolol $(0.5 \mathrm{~g} / \mathrm{kg})$ administered over a period of $1 \mathrm{~min}$. In the adult dog, propranolol produced a significant depression of cardiac index and peak LV systolic pressure, significant elevation of systemic resistance index and LV end-diastolic pressure, and a significant fall in indices of myocardial contractility. The changes in heart rate, cardiac index, peak LV systolic pressure, and contractility indices produced by propranolol were 2-4 times greater, on a percentage basis, in the puppies as in the adult dogs. The systemic resistance index and LV end-diastolic pressure changed similarly in both groups. The increased sensitivity of the puppies to propranolol appears to reflect a greater dependence on circulating catecholamines in the immature circulation.
\end{abstract}

\section{Speculation}

A greater depression of the cardiovascular function, induced by propranolol, is shown in puppies as compared with adult dogs. This is thought to reflect either an increased dependence of the puppy circulation on circulating catecholamines, or an increased sensitivity to the known myocardial depressant effects of propranolol.

\section{Introduction}

The role of the sympathetic nervous system in the regulation of cardiovascular function has been extensively studied in adult humans and animals, but is less well understood in immature animals. Downing $e t$ al. [4] have demonstrated that newborn lambs respond appropriately to sympathetic nerve stimulation, both chronotropically and inotropically. On the other hand, histochemical studies have suggested that cardiac sympathetic innervation is not complete at birth [6].
Previous studies [22] have reported the incidence of cardiomegaly, bradycardia, and signs of cardiac failure in infants and children with tetralogy of Fallot undergoing treatment with propranolol, a beta blocking agent, for the prevention of hypoxic spells. The occurrence of heart failure in these patients, induced by doses of propranolol equivalent to the ones employed to produce beta blockade in adult patients, would suggest an increased sensitivity of the circulatory system in the less mature subjects. 
In order to evaluate the sensitivity of the immature circulation to the chronotropic and inotropic effects of propranolol, as compared with the adult subjects, the present study was undertaken.

\section{Materials and Methods}

Thirteen adult mongrel dogs $(8.6-25 \mathrm{~kg})$, and 14 mongrel puppies $3-8$ weeks of age $(0.7-1.9 \mathrm{~kg})$, were anesthetized with chloralose, $50 \mathrm{mg} / \mathrm{kg}$ intravenously, and morphine sulfate, $1 \mathrm{mg} / \mathrm{kg}$. Ventilatory support was provided with a volume respirator [25]; in the small animals inspiration occupied one-third of the total cycle. The frequency and tidal volume were selected according to the nomogram of Kleinman and Radford [25].

Catheters were inserted into each jugular vein and passed into the right atrium. A catheter tip pressure transducer [26] was inserted into the right carotid artery and advanced under fluoroscopic control into the left ventricle. In the adult animals a no. 7 Lehman catheter and in the puppies a no. 5 Lehman catheter [27] was advanced into the left ventricle from the left carotid artery. The animals were heparinized and the catheters were flushed periodically with heparinized Ringer's lactate solution. The catheter tip transducer and the Lehman catheter attached to a Statham

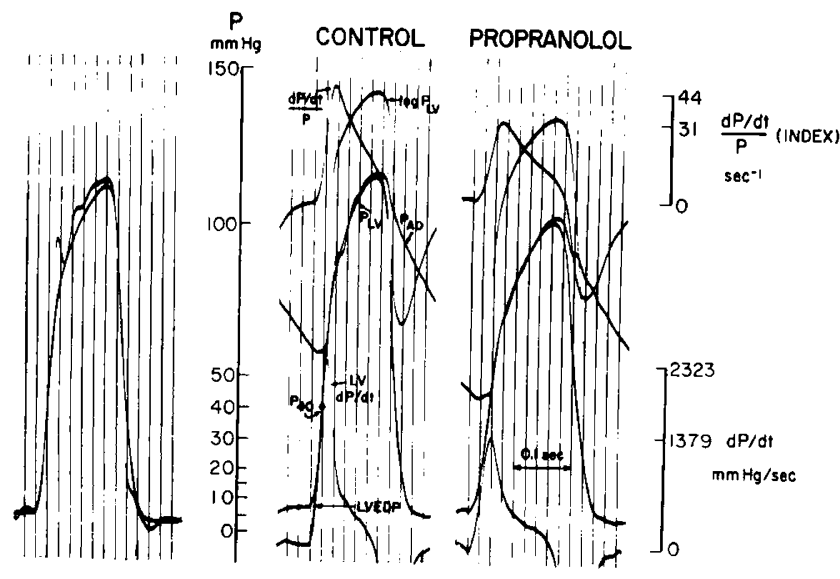

Fig. 1. Representative record of pressure tracings in a puppy. Left panel: superimposition of left ventricular pressure tracing from a catheter tip manometer (smooth curve) and a conventional catheter-manometer system. Middle panel: simultaneous recording of control left ventricular pressure $\left(P_{L F}\right)$, aortic pressure $\left(P_{A O}\right)$, rate of left ventricular pressure development $(d P / d t), \log P_{L V}$, and rate of change of $\log \mathrm{P}_{\mathrm{L}}\left(\frac{d P / d t}{P}\right)$ (Reference 11). Right panel: recording $5 \mathrm{~min}$ after propranolol $0.5 \mathrm{mg} / \mathrm{kg}$, given intravenously. LVEPD: left ventricular end-diastolic pressure.
$\mathrm{P} 23 \mathrm{Db}$ strain gauge, were connected to SGM pressure channels of a recorder [28]. The left ventricular pressure pulse from each catheter was displayed simultaneously on the recorder oscilloscope (Fig. 1). The conventional catheter-manometer system was zeroed at midthoracic level and calibrated in the usual fashion, and the tip manometer recording was referred to this calibration. The Lehman catheter was then withdrawn into the aorta for the remainder of the study.

The rate of development of left ventricular pressure was obtained by connecting the differentiator output of the tip manometer channel to a DC channel. The differentiator circuit was calibrated by recording the $\mathrm{dp} / \mathrm{dt}$ deflection in response to an electronic signal of steep constant slope. A continuous recording of $(\mathrm{dp} /$ $\mathrm{dt}) / \mathrm{P}$ was obtained electronically by the method of Grossman et al. [12]. The pressure pulses and the LV $\mathrm{dp} / \mathrm{dt}$ and $(\mathrm{dp} / \mathrm{dt}) / \mathrm{P}$ were recorded photographically at a paper speed of $200 \mathrm{~mm} / \mathrm{s}$ with time lines at $0.02-\mathrm{s}$ intervals (Fig. 1). The $P_{40} \mathrm{dp} / \mathrm{dt}$ was obtained from the simultaneous tracings of $\mathrm{LV}$ pressure and $\mathrm{LV} \mathrm{dp} /$ dt.

Cardiac output was measured by the indicator dilution technique using indocyanine green, which was injected into the right atrial catheter from a calibrated delivery tube with a saline flush. In the puppies, blood was withdrawn from the aortic catheter through a cuvette densitometer [29] at a rate of $7.0 \mathrm{ml} / \mathrm{min}$ and was returned to the animal through the right atrial catheter on the side opposite the dye injection by means of a Polystaltic pump [30]. This continuous flow system was primed with heparinized, freshly drawn maternal blood. In the adult dogs blood was withdrawn from the aortic catheter through the cuvette densitometer by a motor-driven syringe [31] at a rate of $19 \mathrm{ml} / \mathrm{min}$. The indicator dilution curves were recorded on a direct writing instrument [32] and cardiac output was calculated from the area under the extrapolated curve by the Stewart-Hamilton formula in the usual fashion.

Systemic resistance index was calculated in arbitrary units as the aortic mean pressure divided by the cardiac index.

After control measurements of cardiac output, left ventricular and aortic pressures, $L V d p / d t$, and $(\mathrm{dp} /$ $\mathrm{dt}) / \mathbf{P}$, propranolol was administered intravenously in a dose of $0.5 \mathrm{mg} / \mathrm{kg}$ body wt over a period of $1 \mathrm{~min}$. All the measurements were repeated $5 \mathrm{~min}$ after the injection. In four of the puppies, after the initial fall in heart rate after propranolol administration, cardiac pacing was carried out by means of a ventricular elec- 
Table $I$. Hemodynamic effects of propranolol in adult dogs and puppies ${ }^{1}$

\begin{tabular}{|c|c|c|c|c|c|c|c|}
\hline & Body wt, $\mathrm{kg}^{2}$ & $\begin{array}{l}\text { Heart rate, } \\
\text { beats } / \text { min }\end{array}$ & $\mathrm{CI}, \mathrm{cc} / \mathrm{min} / \mathrm{kg}$ & $\begin{array}{l}\text { Stroke work, } \\
\text { g-m/beat }\end{array}$ & PLVSP, mm Hg & SRI & LVEDP, $\mathrm{mm} \mathrm{Hg}$ \\
\hline \multicolumn{8}{|c|}{ Adult dogs $(n=13$, mean $\pm \mathrm{sD})$} \\
\hline Control & $\begin{array}{l}14.9 \\
(4.5)\end{array}$ & $\begin{array}{c}90 \\
(18)\end{array}$ & $\begin{array}{l}121 \\
(24)\end{array}$ & $\begin{array}{c}23.64 \\
(12.96)\end{array}$ & $\begin{array}{l}151 \\
(23)\end{array}$ & $\begin{array}{c}1.18 \\
(0.27)\end{array}$ & $\begin{array}{l}8 \\
(2.7)\end{array}$ \\
\hline Propranolol & & $\begin{array}{c}83 \\
(16)\end{array}$ & $\begin{array}{l}105 \\
(29)\end{array}$ & $\begin{array}{c}22.22 \\
(14.59)\end{array}$ & $\begin{array}{l}147 \\
(24)\end{array}$ & $\begin{array}{c}1.35 \\
(0.40)\end{array}$ & $\begin{array}{l}11 \\
(4.1)\end{array}$ \\
\hline$P$ & & N.S. & $<0.01$ & N.S. & $<0.05$ & $<0.05$ & $<0.01$ \\
\hline \multicolumn{8}{|c|}{ Puppies $(n=14$, mean $\pm \mathrm{sD})$} \\
\hline Control & $\begin{array}{c}1.1 \\
(0.4)\end{array}$ & $\begin{array}{l}213 \\
(36)\end{array}$ & $\begin{array}{l}215 \\
(58)\end{array}$ & $\begin{array}{l}0.84 \\
(0.420)\end{array}$ & $\begin{array}{c}99 \\
(16)\end{array}$ & $\begin{array}{c}0.45 \\
(0.16)\end{array}$ & $\begin{array}{c}9 \\
(6.2)\end{array}$ \\
\hline Propranolol & & $\begin{array}{l}162 \\
(38)\end{array}$ & $\begin{array}{l}154 \\
(68)\end{array}$ & $\begin{array}{l}0.73 \\
(0.425)\end{array}$ & $\begin{array}{c}82 \\
(20)\end{array}$ & $\begin{array}{c}0.54 \\
(0.21)\end{array}$ & $\begin{array}{l}12 \\
(8.2)\end{array}$ \\
\hline$P$ & & $<0.01$ & $<0.01$ & N.S. & $<0,01$ & $<0.05$ & $<0.01$ \\
\hline
\end{tabular}

1 CI : cardiac index; PLVSP : peak left ventricular systolic pressure; SRI : systemic resistance index; LVEDP: left ventricular enddiastolic pressure; N.S.: not significant.

${ }^{2} \mathrm{SD}$ is indicated within parentheses.

trode catheter. In this manner, the heart was paced at the same rate observed before propranolol in order to evaluate the changes in ventricular contractility, $[(\mathrm{dp} /$ dt) $(\mathrm{dp} / \mathrm{dt})] / \mathbf{P}$, induced by the negative inotropic effect of this agent independently of changes in heart rate.

The change in each variable after propranolol was analyzed statistically by means of the paired $t$ test. The response of the adult dogs and puppies was compared for each variable by means of an unpaired $t$ test.

Samples of arterial blood were removed anaerobically during the study period and analyzed for $\mathrm{pH}$, $\mathbf{P}_{\mathrm{CO}_{2}}$, and bicarbonate by the Sigaard-Anderson technique [20]. The ventilatory tidal volume was adjusted and sodium bicarbonate was administered when necessary to correct gross acid base abnormailites.

\section{Results}

The control values for the cardiovascular variables measured, and the values after propranolol are given in Tables I and II. Comparison of the percentage changes, in both groups of animals, after propranolol are shown in Figure 2.

Propranolol administered intravenously in the dosage employed was well tolerated by all of the adult dogs, but resulted in complete cardiovascular collapse within a few minutes in three puppies. The latter experiments are not included in the final averages.

There was a slight fall in heart rate, averaging $8 \%, 5$ min after propranolol in the adult dogs $(P<0.05)$, whereas heart rate decreased by $24 \%(P<0.01)$ in the puppies. The cardiac output fell significantly $(P<$ 0.01 ) in both groups. The magnitude of fall in both heart rate and cardiac index was significantly greater
Table II. Effects of propranolol on left ventricular contractility ${ }^{1}$

\begin{tabular}{|c|c|c|c|}
\hline & $\begin{array}{l}\text { Peak dp/dt, } \\
\text { mm Hg/s }\end{array}$ & $\begin{array}{l}P_{40} \mathrm{dp} / \mathrm{dt}, \\
\mathrm{mm} \mathrm{Hg} / \mathrm{s}\end{array}$ & Peak $\left.\underset{\mathrm{s}^{-1}}{\mathrm{dp}} / \mathrm{dt}\right) / \mathbf{P}^{2}$ \\
\hline \multicolumn{4}{|c|}{ Adult dogs $(n=13)$} \\
\hline Control & $2789 \pm 390$ & $1696 \pm 397$ & $38.3 \pm 7.5$ \\
\hline Propranolol & $2309 \pm 340$ & $1516 \pm 297$ & $33.0 \pm 7.0$ \\
\hline$P$ & $<0.01$ & $<0.05$ & $<0.01$ \\
\hline \multicolumn{4}{|c|}{ Puppies $(n=14)$} \\
\hline Control & $1975 \pm 463$ & $1583 \pm 520$ & $42.3 \pm 12.8$ \\
\hline Propranolol & $1195 \pm 394$ & $1073 \pm 352$ & $26.6 \pm 10.4$ \\
\hline$P$ & $<0.01$ & $<0.01$ & $<0.01$ \\
\hline
\end{tabular}

${ }^{1}$ Values are means $\pm 1 \mathrm{sD}$.

${ }^{2} n=$ seven puppies, six adult dogs.

in the puppies than in the adult dogs $(P<0.01)$. Peak LV systolic pressure decreased in both the adult dogs $(P<0.05)$ and the puppies $(P<0.01)$; the fall was significantly greater in the puppies than in the adult $\operatorname{dogs}(P<0.05)$. Systemic resistance index and LV end-diastolic pressure increased significantly $(P<0.01)$ in both groups, by approximately the same degree $(P$ $<0.05)$.

Peak LV dp/dt either preceded or occurred simultaneously with aortic valve opening in all experiments. Peak LV dp/dt and (dp/dt)/P decreased significantly $(P<0.01)$ after propranolol administration in both groups. The fall in $\mathrm{dp} / \mathrm{dt}$ was twice as great $(P<0.05)$ and the fall in $(\mathrm{dp} / \mathrm{dt}) / P 3$ times as great $(P<0.05)$ in the puppies as in the adult dogs. The fall in $P_{40} \mathrm{dp} / \mathrm{dt}$ after propranolol was more than twofold greater in the puppies than in the adult dogs $(P<0.05)$.

In the four puppies in which cardiac pacing was employed, the heart rate fell from control values of 


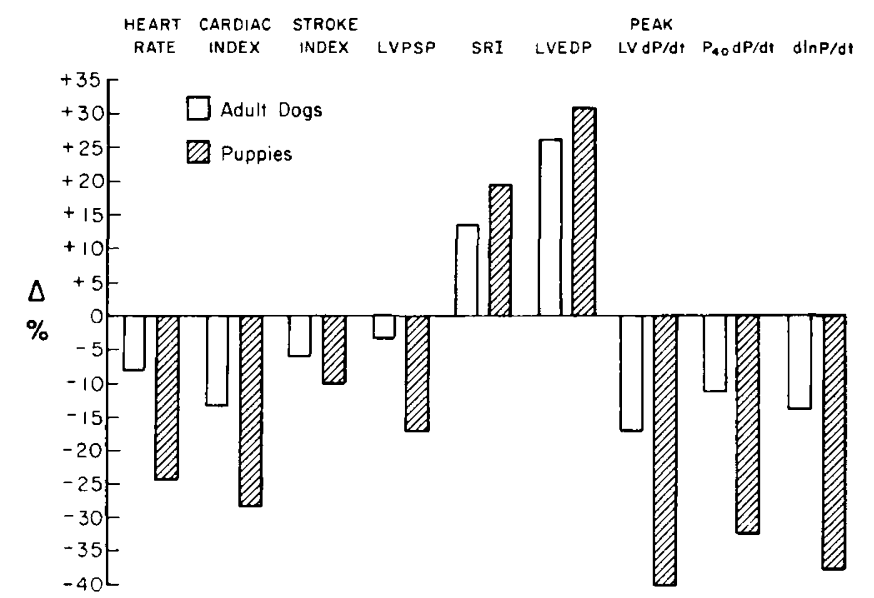

Fig. 2. Cardiovascular effects of propranolol in puppics and adult dogs. Comparison of percentage changes in heart rate, cardiac index, peak left ventricular systolic pressure (LVPSP), systemic resistance index $(S R I)$ left ventricular end-diastolic pressure $(L V E D P)$ peak $\mathrm{dp} / \mathrm{dt}, \mathrm{P}_{40} \mathrm{dp} / \mathrm{dt}$, and $(\mathrm{dp} / \mathrm{dt}) / \mathbf{P}$ in puppies (crosshatched bars) and adult dogs (open bars), after $0.5 \mathrm{mg} / \mathrm{kg}$ propranolol given intravenously. The numbers on the ordinate express percentage changes.

$180-208 / \mathrm{min}$ to $156-171 / \mathrm{min}$ after propranolol. In each case, return of the heart rate to the control value did not produce a significant alteration of the contractility indices from the values obtained after propranolol at lower heart rates.

\section{Discussion}

Previous studies have shown that propranolol produces a dose-related negative chronotropic and inotropic effect in adult dogs. The initial fall in heart rate, cardiac index, and myocardial contractility observed with the lower doses of propranolol $(0.5 \mathrm{mg} / \mathrm{kg})$ appear to be related to the sympathetic beta blocking effect of this agent [9]. Further falls in these variables with higher doses of propranolol seem to be related to an intrinsic direct negative chronotropic and intropic effect of propranolol, independent of the beta blocking properties of this drug [9].

The present results indicate that the relative propranolol sensitivity of the cardiovascular system in the immature versus the adult subjects in the mongrel dog appears to be different.

The control values for heart rate, blood pressure, and cardiac index in the present experiments are comparable with data available for unanesthetized dogs and puppies [1]. Our observations indicate that in 11 mongrel puppies $(1.6 \pm 0.2 \mathrm{~kg})$, the control heart rate,
$188 \pm 14$ beats/min, was not significantly altered by the induction of chloralose-morphine anesthesia (193 \pm 13 after anesthesia).

The dose of propranolol employed in this study, that is, $0.5 \mathrm{mg} / \mathrm{kg}$ body $\mathrm{wt}$, is used commonly to produce beta receptor blockade in experimental animals [7], although this dose is considerably larger than the ones employed for clinical purposes [13-19]. Because the total body surface area relative to body weight is greater in the immature than the mature animal, a fixed dose of propranolol based on body weight is believed to be pharmacologically smaller in the immature animal [21]. This distinction requires confirmation, however. In the present study propranolol reduced both the heart rate and the cardiac index by approximately $10 \%$ in the adult dogs and $25 \%$ in the puppies. In previous studies beta blockade in adult humans produced a $10-15 \%$ reduction in heart rate and cardiac inclex [14, 23]. Similar findings have been reported in adult dogs [15], while a greater fall has been associated with high initial heart rates [16].

Myocardial contractility was assessed in the present studies by estimates of contractile element velocity derived from the rate of pressure development during isovolumic systole. Peak LV dp/dt is not independent of ventricular preload, and after the opening of the aortic valve, it is also affected by afterload [18]. The $(\mathrm{dP} / \mathrm{dt}) / \mathrm{P}$ is considered to be relatively independent of both preload and afterload, and to correlate well with $V_{\max }[18]$. However, recent evidence suggests that it may be better when related to developed pressure (i.e., total ventricular pressure minus end-diastolic pressure) rather than total pressure $[10,12,17]$. The $P_{40} d p / d t$ has been suggested as an index of contractility that is independent of preload [3]. Nevertheless, these indices have proved useful in the present study and provide similar results, which are confirmed by conventional hemodynamics (Tables I and II).

Although end-diastolic pressure can affect ventricular performance, this variable increased to a similar extent in both the puppies and the adult dogs (Table I), whereas the decrease in $(\mathrm{d} / \mathrm{dt}) / \mathrm{P}$ was 3 times as great for the puppies as for the adult dogs, despite the fact that both groups showed nearly identical changes in $\mathrm{LV}$ end-diastolic pressure and therefore in preload. This suggests a fall in $(\mathrm{dp} / \mathrm{dt}) / \mathbf{P}$ for the puppies well in excess of that induced by the preload alteration alone. Systemic resistance, another determinant of ventricular performance, increased in both groups to a similar extent; however, these changes were not statistically sig- 
nificant when both groups were compared. Stroke work (Table I) decreased in both groups after propranolol. Although this decrease was greater for the puppies, these changes did not achieve statistical significance.

Since increasing heart rate is believed to increase myocardial contractility [8], the present results might in part be related to the observation of a statistically significant decrease in heart rate in the puppies treated with propranolol, while adult heart rate was not significantly changed (Table I). When ventricular pacing was employed in four puppies treated with propranolol, however, returning the heart rate to control values did not alter the contractility indices significantly (Fig. 3). Depression of myocardial contractility in the puppies can therefore not be attributed to the decrease in heart rate induced by propranolol and can be explained by the negative inotropic action of this agent (Fig. 3).

Beta adrenergic blockade causes no significant change in cardiovascular function in the normal, resting adult, but myocardial contractility fails to increase normally during exercise and is significantly depressed in the presence of heart failure [2]. Thus, in the normal adult, adrenergic influences appear to play an important role primarily in maintaining cardiac "reserve" function.

The results of the present study suggest that the immature circulation is more sensitive to the negative chronotropic and inotropic effects of propranolol than the adult counterpart of the same species.

The findings in the present study are compatible with the observations of Friedman [5], which show a greater concentration of myocardial norepinephrine in fetal and newborn rabbits and lambs, as compared with the adult animals in the same species, as well as a greater depression of contractility of fetal myocardium as compared with adults, induced by propranolol in isolated muscle preparations. Supersensitivity to norepinephrine would be expected if the myocardium of fetuses and neonates lacked a complete development of sympathetic innervation or if sympathetic nerves within these young hearts had a reduced capacity to take up and bind catecholamines [5]. Uptake and binding represent an important mechanism for the inactivation of norepinephrine, and it would be anticipated that the reduction in the ability of the heart to utilize this mechanism of inactivation would permit a higher concentration of the neurotransmitter to reach and activate the beta receptors of the heart, and therefore render the heart supersensitive (5).

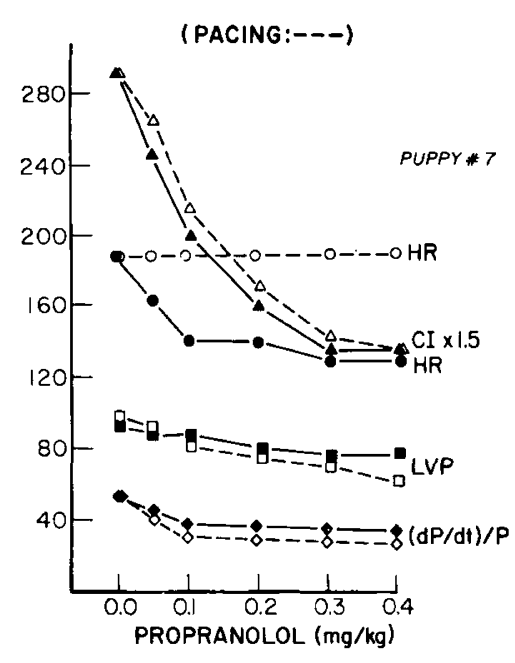

Fig. 3. Representative example of a propranolol dose response curve with cardiac pacing in a puppy (four experiments), with return of the heart rate $(H R)(---)$ to the control values after each dose of propranolol (in milligrams per kilogram), indicated on the abscissa. Note that the decrease in cardiac output $(C I)$ and $(\mathrm{dp} / \mathrm{dt}) / \mathbf{P}$ after each dose of propranolol is not significantly affected by returning the heart rate to control values. LI'P: left ventricular pressure.

Undoubtedly, propranolol has a place in the management of heart diseases in children. However, the results of the present study, showing a marked depression of myocardial contractility, heart rate, and cardiac output in puppies suggest that caution must be exercised in use of this agent in young infants and children.

\section{References and Notes}

1. Biological Handbook. Respiration and Circulation.

2. Braunwald, E., Ross, J., Jr., and Sonnenblick, E. H.: Mechanisms of Contraction of the Normal and Failing Heart (Little, Brown, Boston, 1967).

3. Covell, J. W.: Personal communication.

4. Downing, S. E., Talner, N. S., Campbell, A. G. N., HalloRAN, K. H., AND WAX, H. B.: Influence of sympathetic nerve stimulation on ventricular function in the newborn lamb. Circ. Res., 25: 417 (1969).

5. Friedman, W. F.: Neonatal Heart Disease, p. 41 (Grune \& Stratton, Inc., New York, 1973).

6. Friedman, W. F., Pool, P. E., Jacobowitz, D., Seagren, S. S., AND Braunwald, E.: Sympathetic innervation of the developing rabbit heart. Circ. Res., 23: 25 (1968).

7. Gander, M., Veragut, U., Kohi.er, R., and Jutby, E.: Cardiac hemodynamics under beta-receptor blockade in dogs. Cardiologia (Suppl. II), 49: 17 (1966).

8. Glick, G., Sonnenblick, E. H., And Braunwald, E.: Myocardial force-velocity relations studied in intact unanesthetized man. J. Clin. Invest., 44: 978 (1965).

9. Goldstein, R. E., Hall, C. A., and Epstein, S. E.: Comparison of relative inotropic and chronotropic effects of propranolol, practolol and sotalol (Abstract). Clin. Res., 19: 316 (1971). 
10. Graham, T. P., Jr., Jarmakani, J. M., Canent, R. V., JR., and Anderson, P. A. W.: Evaluation of left ventricular contractile state in childhood. Circulation, 44: 1043 (1971).

11. Grossman, W., Brooks, H., Meister, S., Sherman, H., and Dexter, L.: New technique for determining instantaneous myocardial force-velocity relations in the intact heart. Circ. Res., 28: 290 (1971)

12. Grossman, W., Haynes, F., Paraskos, J. A., Saltz, S., Dalen, J. E., AND DEXTER, L.: Alterations in preload and myocardial mechanics in the dog and in man. Circ. Res., 31: 83 (1972).

13. Harrison, D. C.: Beta adrenergic blockade. Amer. J. Cardiol., 29: 432 (1972).

14. Helfant, R. H., Herman, M. V., and Gorlin, R.: Abnormalities of left ventricular contraction induced by beta adrenergic blockade. Circulation, 43: 641 (1971).

15. Keroes, J., ECKER, R. R., AND RAPAPORT, E.: Ventricular function curves in the exercising dog. Circ. Res., 25: 557 (1969).

16. Nies, A. S., McNeIL, J. S., ANd Schrier, R. W.: Mechanism of increased sodium reabsorption during propranolol administration. Circulation, 44: 596 (1971).

17. NoBle, M. I. M.: Problems concerning the application of concepts of muscle mechanics to the determination of the contractile state of the heart. Circulation, 45: 252 (1972).

18. Parmley, W. W., Chuck, L., and Sonnenblick, E. H.: Relation of $\mathrm{V}_{\max }$ to different models of cardiac muscle. Circ. Res., 30: 34 (1972).

19. Shand, D. G., Sell, C. G., and Oates, J. A.: Hypertrophic obstructive cardiomyopathy in an infant: Propranolol therapy for three years. New Engl. J. Med., 285: 843 (1971).
20. SigaArd-Andersen, O.: The Acid-Base Status of the Blood, Ed. 3 (The Williams \& Wilkins Co., Baltimore, 1966).

21. Talbot, N. B., Richie, R. H., and Crawford, J. D.: Metabolic Homeostasis (Harvard University Press, Cambridge, Mass. 1959).

22. Williams, L. C., Webb, H. M., ANd Hohn, A.: Propranolol palliation of tetralogy of Fallot (Abstract). Presented at The 40th Annual Meeting of the American Association of Phy. sicians, Chicago, October 1971.

23. Wolfson, S., AND Gorlin, R.: Cardiovascular pharmacology of propranolol in man. Circulation, 40:501 (1969).

24. Supplied by Ayerst Laboratories, Montreal, Quebec, Canada.

25. Harvard Apparatus Co., Millis, Mass.

26. Model PC-300, Millar Instrument Co., Dallas, Tex.

27. U. S. Catheter \& Instrument Corp., Glens Falls, N. Y.

28. Model DR ${ }^{8}$, Electronics for Medicine, Inc., White Plains, N. Y.

29. Model XP302, Waters Co., Rochester, Minn.

30. Buchler Instruments, Inc., Fort Lee, N. J.

31. Sage Instruments, Inc., White Plains, N. Y.

32. Texas Instruments, Inc., Houston, Tex.

33. This work was supported by an National Institutes of Health Training Grant no. HE 05389-12 in Pediatric Cardiology and by the Babies Hospital Cardiac Research Fund.

34. Requests for reprints should be addressed to: Nestor J. TRUCCONE, M.D., Department of Pediatrics, Columbia University College of Physicians and Surgeons, 622 W. 168th St., New York, N. Y. (USA).

35. Accepted for publication July 5, 1973. 